\title{
O VAIVÉM DAS MEMÓRIAS EM OLHOS D'ÁGUA, DE CONCEIÇÃO EVARISTO
}

\author{
Elen Karla Sousa da Silva* \\ Daniel Conte
}

RESUMO: Este trabalho analisa os rastros da memória, em Olhos d'água (2015), de Conceição Evaristo. A obra apresenta diversas histórias de dor, violência, pobreza, ancestralidade, carregadas de expressividades que expõem o resgate identitário da mulher negra, através das memórias individual e/ou coletiva. Na obra em estudo a memória percorre as exclusões sofridas pelas protagonistas e, ocasionalmente, é praticada também pelos narradores, e de modo particular, é evidenciada a prática de reconhecer o passado. Evaristo, tendo como base a memória, ressignifica a posição dos negros na sociedade brasileira, tentando desconstruir pensamentos estereotipados sobre o negro, reescreve histórias que se compõem na heterogeneidade e diversidade social. Nessa perspectiva, travamos uma discussão sobre memória, através da revisitação a um passado que permanece vivo e presente por meio da oralidade e de uma linguagem poética que permeia toda a obra, por meio de ocorrências cotidianas e peregrinações.

PALAVRAS-CHAVE: Memória. Olhos d'água. Conceição Evaristo.

* Doutoranda do Programa de Pós-Graduação em Letras da Universidade federal do Rio Grande do Sul (UFRGS). Bolsista CNPq.

** Doutor em Literatura Brasileira, Portuguesa e Luso-africanas pela Universidade Federal do Rio Grande do Sul (UFRGS). Professor e Pesquisador da Universidade Feevale. PQ-CNPq. 


\section{Rastros da memória}

\section{Recordar é preciso \\ O mar vagueia onduloso sob os meus pensamentos A memória bravia lança o leme: Recordar é preciso. \\ O movimento vaivém nas águas-lembranças dos meus marejados olhos transborda-me a vida, salgando-me o rosto e o gosto. Sou eternamente náufraga, mas os fundos oceanos não me amedrontam e nem me imobilizam. Uma paixão profunda é a boia que me emerge. Sei que o mistério subsiste além das águas.} (EVARISTO, 2011, p. 17)

Momentos tão dolorosos que ligam o presente e o passado aos prantos dos antepassados de uma nação na qual o martírio subsiste por gerações. Desse modo, Conceição Evaristo expõe sentimentos incitados pela recordação da época em que era uma criança; tempo que irá refletir em seu modo de escrita no vindouro. "Das acontecências do banzo, em determinados casos, nada pode ser feito para se escapar, a não ser viver...” (EVARISTO, 2008, p. 57).

Para Pollak (1989, p. 8), “o que está em jogo na memória é também o sentido da identidade individual e do grupo", e deve ser inscrita com base no ponto de vista do negro e não por uma memória oficial que não concebe as verdadeiras vivências deste grupo. Todos os povos, os imigrantes, gostam de relembrar o passado e possuem a oportunidade de rememorar. Os povos diaspóricos podem se valer de suas culturas, memórias e ancestrais, até como material estético para se trabalhar a literatura e para se fortalecer. Evaristo acredita que essas histórias, essas reminiscências não podem se perder, ser esquecidas, são histórias exemplares, são paradigmas para o sujeito atual, por isso a necessidade da valorização da memória e da ancestralidade na ficção.

Os negros e afrodescendentes teceram suas identidades e, através das rememorações, reestruturaram suas vidas delineando novas estruturas culturais ocorridas da sua condição em terras peregrinas. "A lembrança reaparece em função de muitas séries de pensamentos coletivos emaranhados" (HALBWACHS, 2006, p. 70). Assim sendo, cada grupo 
seleciona os subsídios que irão compor sua memória ou seus ambientes de memória. Espaços que serão atenciosamente constituídos com o intuito de torná-los singulares. Conforme Halbwachs:

\begin{abstract}
Nós nos surpreendemos ao reencontrar essa lembrança, mas após um momento de reflexão, poderíamos também nos espantar por não a termos evocado antes, ao descobrirmos no labirinto de nossos pensamentos mais de uma avenida que a ela nos levariam. Esse lugar, esses objetos nos trazem essa lembrança. (HALBWACHS, 2006, p. 54)
\end{abstract}

Ricoeur (2007) afirma que a memória, distinta da imaginação, está relacionada a momentos anteriores, às lembranças do passado, que advêm das memórias individuais e coletivas. A partir das concepções de Halbwachs (2006), mesmo que as memórias não tenham sido restauradas, quando invocadas são armazenadas em nossa alma. Ademais, o autor garante que para que as falas de outras pessoas sejam aproveitadas em nossas memórias é preciso que haja questões análogas que nos permitam rememorar e que sejam restauradas sobre um alicerce comum. Isto é, mesmo sem a existência de outro indivíduo, podemos falar de memória coletiva ao evocarmos episódios que fazem referência à vivência de determinado grupo.

No conto em estudo, narrado em primeira pessoa, a narradora vai ao encontro de seus ancestrais no decorrer do enredo. Em Olhos d'água, Evaristo aflora sua emotividade. Enfatizamos que o conto tem como base uma indagação: “- De que cor eram os olhos de minha mãe?” (EVARISTO, 2015, p. 17). Fazendo uso desse questionamento, a autora segue o enredo da infância à fase adulta, rememorando a presença materna diante dos infortúnios, dos quais podemos citar: a pobreza, a fome e o receio de não conseguir criar as filhas.

Ademais, a vulnerabilidade comum ao povo marginalizado é retratada no conto, onde inclusive o direito a uma morada digna é negado: " - Lembro-me ainda do temor de minha mãe nos dias de fortes chuvas. [...] temendo que o nosso frágil barraco desabasse [...]" (EVARISTO, 2015, p. 17). Evidencia-se, além disso, no decorrer do conto, ser notória 
uma memória ancestral que se faz presente e que é assinalada por marcas ancestrais e matriarcais: “ - Mas, eu nunca esquecera a minha mãe. Eu reconhecia a importância dela na minha vida, não só dela, mas de minhas tias e de todas as mulheres da minha família. [...] Não, eu não esqueço essas Senhoras, nossas Yabás, donas de tanta sabedoria” (EVARISTO, 2015, p. 18). Observa-se ainda o resgate de uma memória ancestral: “— [...], já naquela época, eu entoava cantos de louvor a todos os nossos ancestrais, que desde a África vinham arando a terra da vida com as suas próprias mãos, palavras e sangue” (EVARISTO, 2015, p. 18).

Nessa narrativa, nota-se o aparecimento de nuvens e lágrimas, sendo uma temática rotineira na produção de Evaristo. Visto que as nuvens denotam no enredo a utopia de preencherem o vazio da fome; as lágrimas, que no decorrer da narrativa eram de angústia, ao término são de alegria, face ao reencontro com a filha. O céu reverberado nas águas das tinas e bacias mescla fantasia e expectativa à realidade.

[...] após longos dias de viagem para chegar à minha terra, pude contemplar extasiada os olhos de minha mãe, sabem o que vi? Sabem o que vi? Vi só lágrimas e lágrimas. Entretanto, ela sorria feliz. Mas, eram tantas lágrimas, que eu me perguntei se minha mãe tinha olhos ou rios caudalosos sobre a face? E só então compreendi. Minha mãe trazia, serenamente em si, águas correntezas. Por isso, prantos e prantos a enfeitar o seu rosto. A cor dos olhos de minha mãe era cor de olhos d'água. Águas de Mamãe Oxum! Rios calmos, mas profundos e enganosos para quem contempla a vida apenas pela superfície. Sim, águas de Mamãe Oxum. (EVARISTO, 2015, p. 18-19)

Outro aspecto interessante diz respeito às brincadeiras, que são ligadas à pobreza, à triste realidade que viviam:

Nessas ocasiões a brincadeira preferida era aquela em que a mãe era a Senhora, a Rainha. Ela se assentava em seu trono, um pequeno banquinho de madeira. Felizes colhíamos flores cultivadas [...] que eram solenemente distribuídas por seus cabelos, braços e colo. [...] e juntas ficávamos contemplando as artes das nuvens no céu. Umas viravam carneirinhos, outras cachorrinhos, algumas gigantes adormecidos e havia aquelas que eram só nuvens, algodão doce [...] (EVARISTO, 2015, p. 17) 
Observa-se, a partir do título, que Evaristo faz uso da imagem dos olhos para atribuir um sentido poético à narrativa. É através da imagem dos olhos que se suscitam, na voz narrativa, as memórias referentes a sua fase puerícia, como um angustiante quebracabeças. Dessa forma, aflora a necessidade do reencontro com sua mãe; em seguida, com sua gênese. Em Olhos d'água Evaristo apresenta indagações de categoria religiosa, social e cultural, ligadas a mazelas em que a voz narrativa está situada desde a infância, e refletindo sobre sua relação com yabás africanos, com seus orixás. Assim, Evaristo introduz a voz autoral, o assunto abordado e suas concepções, sem se descuidar da estética em sua escrita, distanciando-se de um conteúdo "panfletário".

A memória desencadeia não apenas as recordações de um passado histórico, contudo, recupera uma lembrança que contribui para uma construção feminina identitária negra, envolvida em subalternidade, que deixa o silêncio para dar lugar a uma voz significativa. Compreende-se que a memória é mesclada por lembranças de cada ser; entretanto, decorrida pelos pensamentos de um grupo. Com traços nas recordações de Evaristo, quando profere: "mamãe contava, minha tia contava, meu tio velhinho contava e os vizinhos contavam, eu menina repetia, contava" (EVARISTO, 2009). Enfatiza-se a relevância dos familiares e todos ao seu redor como referência basilar para a constituição desta memória individual e coletiva. Le Goff ressalta que a noção de memória coletiva foi exposta de maneira relevante na:

Luta das forças sociais pelo poder. Tornarem-se senhores da memória e do esquecimento é uma das grandes preocupações das classes, dos grupos e dos indivíduos que dominam as sociedades históricas. Os esquecimentos e os silêncios da história são reveladores desses mecanismos de manipulação da memória coletiva. (LE GOFF, 2012, p. 408)

Evaristo delineia, desse modo, os percursos das protagonistas, considerando suas afeições, desamores e sua ligação com os familiares e pessoas próximas. Ao narrar suas recordações, a narradora de Olhos d'água rememora as vivências que foram importantes para sua infância, embaralhando suas próprias memórias com as recordações de sua mãe: 
[...] Às vezes, as histórias da infância de minha mãe confundiam-se com as de minha própria infância. Lembro-me de que muitas vezes, quando a mãe cozinhava, da panela subia cheiro algum. Era como se cozinhasse, ali, apenas o nosso desesperado desejo de alimento. (EVARISTO, 2015, p. 16)

$\mathrm{Na}$ passagem acima, as memórias se entrelaçam e uma discussão recorrente e temas constantes na vida da narradora despontam: a escassez, a fome, a penúria. Ao expor os problemas vividos pela narradora protagonista, Evaristo adentra a discussão inserida na história contemporânea dos afrodescendentes, transpostos pela pobreza, pelos dramas sociais.

O sentido de denúncia apresentado no decorrer do conto reforça a perda identitária e a urgência por reencontrá-la. Apesar de algumas memórias de sua fase puerícia estarem perceptíveis para a voz narrativa, a cor dos olhos que foge de suas rememorações possibilita refletir sobre essa identidade fragmentada. Conforme Chevalier \& Gheerbrant (2012, p. 653), o olho é o "símbolo da percepção intelectual", a figura do olho é transposta por uma esfinge e misticidade; frequentemente costumamos ouvir que "os olhos são a janela da alma”. Percebamos melhor essa simbologia.

Apropriar-se dessas lembranças é reconhecer uma carga hereditária, uma ancestralidade, é estabelecer uma ligação entre passado e futuro que se materializa ao final do enredo, no momento em que a narradora, ao brincar com sua filha, intenciona deslindar a real cor de seus olhos. A assimilação, desse modo, se dá através do olhar, a voz narrativa, tendo descoberto a cor dos olhos de sua mãe, tenta saber a cor dos olhos da filha. É essa, porém, que colabora para o desfecho de tudo, ao questionar: "Mãe, qual é a cor tão úmida de seus olhos?" (EVARISTO, 2015, p. 19), isto é, a narradora tinha os olhos semelhantes aos da mãe, neles se refletia toda uma vivência, toda uma sucessão que se eterniza de geração a geração.

A mãe tinha os olhos de mamãe Oxum, que conforme a tradição africana era a deusa da fertilidade na Terra, e que um certo dia reagiu contra a dominação masculina. De acordo com a história, quando os orixás chegaram a Terra decidiram organizar grupos para 
determinarem as atividades; porém as mulheres não poderiam compor tais ações. Oxum, irritada com essa deliberação, tornou inférteis as mulheres; além disso, secou fontes de águas e, por conseguinte, a terra se tornou improdutiva. Desse modo, os orixás foram forçados a convidá-la a fazer parte dos encontros, e finalmente a fertilidade foi restituída na Terra.

Destaca-se ainda o elemento água, que é o componente fundamental no conto, representado através do choro, que é dor, entretanto, é também obstinação. Nessa perspectiva, pensar sobre os olhos e na dubiedade deles, é considerar a forma como a voz narrativa percebe a si mesma e o âmbito em que está inserida, e as indagações que permeiam este olhar. Verifica-se nesta conjectura de interpretação a analogia que a narradora estipula entre o seu regresso à casa e um ritual aos orixás: “- Vivia a sensação de estar cumprindo um ritual, em que a oferenda aos Orixás deveria ser a descoberta da cor dos olhos de minha mãe" (EVARISTO, 2015, p. 18). Ao comparar a voz narrativa, evidencia e ratifica a relevância da descoberta, onde deixa de ser uma incerteza e se torna um anseio, um compromisso. Conectada à voz autoral, a discussão existente na narrativa estabelece um diálogo com a herança ancestral e a identidade negra, recorrendo-se à imagem dos olhos para denotar a união entre passado e presente, que transfere a figura da avó à neta.

Ao regressar a casa que viveu durante a infância, finalmente a voz narrativa descobre a cor dos olhos, que estava escondido em virtude da umidade existente neles. O retorno à casa materna pode ser interpretado como uma metáfora da volta à sua gênese. Essa ação confirma a noção de que a voz narrativa, ainda que tenha se afastado dos seus, de seu âmbito familiar, não rompe com os laços que a ligam ao passado.

Já o conto Duzu-Querença promove quebras com o passado. Conceição Evaristo aponta um direcionamento para o futuro. Isso é perceptível quando a personagem Querença, ao reparar a história de vida da avó Duzu e recordar as histórias de seus ancestrais, compreende que é necessário enveredar por outros caminhos, no intuito de conquistar o que a avó não conseguiu e ir além. Querença representa a figura de uma mulher negra que luta por suas causas e tem consciência dessa luta, da mulher com marcas de valores morais 
e ideológicos de sua etnia, tornando-a um tipo distinto e uma nova heroína, segundo assevera Evaristo em seu artigo "Escrevivências da Afro-brasilidade: História e Memória", quando se refere a poesia de Solano Trindade : “[...] a construção de outro modelo de heroicidade, aquela que não passa pela vitória imediata de um sujeito, mas pela resistência contínua de um povo que esse herói representa" (EVARISTO, 1992, s/p).

Nesse conto, a protagonista é exposta como uma mulher louca, prostituída e mendiga. É importante ressaltar que o pai de Duzu-Querença era um sonhador, "queria caminhar para o amanhã" (EVARISTO, 2015, p. 32), ambicionava que a filha tivesse uma vida melhor indo morar na cidade grande. No entanto, Evaristo expõe que ter cidadania é regalia para poucos. Assim, Duzu protagoniza a triste realidade dos menos favorecidos.

O pai de Duzu tinha nos atos a marca da esperança. De pescador que era, sonhava um ofício novo. Era preciso aprender outros meios de trabalhar. Era preciso também dar outra vida para a filha. $\mathrm{Na}$ cidade havia senhoras que empregavam meninas. Ela podia trabalhar e estudar. Duzu era caprichosa e tinha cabeça para leitura. Um dia sua filha seria pessoa de muito saber. E a menina tinha sorte. Já vinha no rumo certo. Uma senhora que havia arrumado trabalho para a filha de Zé Nogueira ia encontrar com eles na capital. (EVARISTO, 2015, p. 32)

Semelhante ao conto Olhos d'água, encontramos em Du₹u-Querença a presença da memória. A avó Duzu, ao morrer, deixa para Querença, sua neta, a memória do seu povo, no intuito que desse continuidade à luta em favor dos seus:

E foi no delírio da avó, na forma alucinada de seus últimos dias que ela, Querença, haveria de sempre umedecer seus sonhos para que eles florescessem e se cumprissem vivos e reais. Era preciso reinventar a vida. Encontrar novos caminhos. Não sabia ainda como. Estava estudando, ensinava as crianças menores da favela, participava do grupo de jovens da Associação de Moradores e do Grêmio da Escola. Intuía que tudo era muito pouco. A luta devia ser maior ainda. Menina Querença tinha treze anos como seu primo Tático que havia ido por aqueles dias. (EVARISTO, 2015, p. 36-37) 
No conto Duحu-Querença, a personagem Duzu é levada pelo pai ao bordel ainda menina. Dona Esmeraldina, proprietária do bordel, havia prometido ao pai da menina que a mesma poderia estudar na cidade grande. Pontuamos que a temática da esperança transcorre toda a narrativa. O pai sustentava a ideia de que a menina, morando na cidade grande, tivesse um futuro próspero. Contudo, essa esperança não se efetiva, embora Duzu tivesse capricho e possuísse uma boa "cabeça para leitura". Em seguida, ao executar a função de empregada doméstica, Duzu se torna prostituta.

Duzu lambeu os dedos gordurosos de comida, aproveitando os últimos bagos de arroz que tinham ficado presos debaixo de suas unhas sujas. Um homem passou e olhou para a mendiga, com uma expressão de asco. Ela lhe devolveu um olhar de zombaria. (EVARISTO, 2015, p. 31)

Nesse âmbito de penúria que Duzu é apresentada ao leitor logo nas primeiras linhas da narrativa. Através das memórias de Duzu, sua história é apresentada, sendo perceptível a mudança de posicionamento destinada às personagens negras na literatura considerada cânone, que concede espaço ao protagonismo na literatura afrodescendente.

O conto Duzu-Querença é permeado de lirismo, como uma linguagem curta, sucinta; contudo, carregada de sentidos. Até mesmo os sentimentos de desgraça, pobreza, fome são expostos de modo poético:

Duzu olhou fundo no fundo da lata, encontrando apenas o espaço vazio. Insistiu ainda. Diversas vezes levou a mão lá dentro e retornou com um imaginário alimento que jogava prazerosamente à boca. Quando se fartou deste sonho, arrotou satisfeita [...] (EVARISTO, 2015, p. 31)

Ademais, as lembranças das relações com os primeiros homens são descritas na narrativa que durante a infância, instigada pela curiosidade na juventude de Duzu, que a conduzia a adentrar os quartos da casa sem pedir permissão, porque "era bom de olhar", pessoas aglomeradas, uns sobre os outros. Até que um certo dia, Duzu encontra um homem em um dos quartos, homem que a torna "mulher", logo Duzu, de modo instintivo, 
aprende a "dançar". Dona Esmeraldina, ao descobrir o feito, impõe que Duzu lhe devolva o dinheiro que ela havia recebido.

A imagem feminina é centrada na representação da mãe, sobretudo como líder de família. Duzu gera nove filhos, que se dispersam pelos morros, becos. Os filhos da protagonista lhe dão alguns netos, entre os quais, três eram seus preferidos. Tático, contudo, “cor vermelho-sangue já se derramava em sua vida" (EVARISTO, 2015, p. 35), falece. A razão não é apresentada no texto, porém, subentende-se que o envolvimento com o tráfico e o uso de armas tenha sido a causa. Destinos despedaçados, vislumbra-se o destino de mestiços e negros, consequência das más situações vividas, da ausência de oportunidades. A neta querida de Duzu se chamava Querença, a qual representa a ligação entre o passado e o futuro; além de representar o tema da esperança delineada no início da narrativa, retomada pela autora. Em Querença, "ancestrais e vitais sonhos haveriam de florescer e acontecer" (EVARISTO, 2015, p. 36).

Duzu profetiza um destino melhor para Querença, para seus descendentes negros, e ao receber a notícia do falecimento da avó, Querença busca nas lembranças o nome dos seus, dos parentes que nem havia conhecido. Nesse momento, a memória individual transfere espaço à memória coletiva, e a herança ancestral passa a ser o símbolo de uma história abarrotada de combates que restauram a escravidão africana, mas que certamente algum dia serão superados:

E foi no delírio da avó [...] que ela, Querença, haveria de sempre umedecer seus sonhos para que eles florescessem e se cumprissem vivos e reais. Era preciso reinventar a vida. Encontrar novos caminhos. Não sabia ainda como. Estava estudando, ensinava as crianças menores da favela, participava do grupo de jovens da Associação de Moradores e do Grêmio da Escola. Intuía que tudo era muito pouco. A luta devia ser maior ainda. (EVARISTO, 2015, p. 36)

Portanto, em Olhos d'água e Duzu-Querença, a busca por uma vida melhor é ponto importante dos textos, sobretudo em Olhos d'água, que surge de uma interrogação fundamental que segue todas as ações da protagonista negra: "De que cor eram os olhos de 
minha mãe?" A imagem da matriarca se impõe: a partir do questionamento sobre a cor dos olhos da mãe, a narradora-personagem recorda momentos de sua infância, um período vivido com dificuldades e adversidades. Embora os problemas econômicos fossem recorrentes, surge a figura de uma mãe capaz de tudo para que as angústias fossem minimizadas, amparando-se novamente do artifício da ilusão para enganar a fome dos filhos.

A produção de Evaristo, através da memória estabelece uma discussão sobre o processo de formação identitária negra. Concluímos que através da memória a escritora apresenta em seus textos suas "escrevivências", que surgem para dar voz as mulheres negras, pobres e sem visibilidade, contribuindo para o reconhecimento identitário. As personagens analisadas, por meio de suas lembranças constroem a memória histórica e sociocultural da mulher negra, e essas ações memoráveis compõem identidades inseridas em um contexto de busca por igualdade.

\title{
THE COME AND GO OF MEMORIES IN OLHOS D'ÁGUA BY EVARISTO CONCEIÇÃO
}

\begin{abstract}
This work analyzes the traces of memory in Conceição Evaristo's Eyes of Water (2015). The work presents several stories of pain, violence, poverty, ancestry, loaded with expressions that expose the identity of the black woman, through individual and / or collective memories. In the work under study, memory traverses the exclusions suffered by the protagonists and, occasionally, is also practiced by the narrators, and in a particular way, the practice of recognizing the past is evidenced. Evaristo, based on memory, reaffirms the position of blacks in Brazilian society, trying to deconstruct stereotyped thoughts about the black, rewrites stories that are composed in heterogeneity and social diversity. In this perspective, we have a discussion about memory, through the revisiting of a past that remains alive and present through orality and a poetic language that permeates the whole work, through daily occurrences and pilgrimages.
\end{abstract}

KEYWORDS: Memory. Olhos d'Agua. Conceição Evaristo.

\section{REFERÊNCIAS}

CHEVALIER, Jean; GHEERBRANT, Alain. Dicionário de símbolos: mitos, sonhos, costumes, gestos, formas, figuras, cores, números. 23. ed. Rio de Janeiro: José Olympio, 2012.

EVARISTO, Conceição. Olhos d'água. Rio de Janeiro: Pallas, 2015. 
- Conceição por Conceição Evaristo. Depoimento concedido durante o I Colóquio de Escritoras Mineiras, realizado em maio de 2009, na Faculdade de Letras da UFMG, cópia retirada do site: LITERAFRO. Disponível em: www.letras.ufmg.br/leterafro. Acesso em: 11 jul. 2018.

. Poemas da recordação de outros movimentos. Belo Horizonte: Nandyala, 2011.

. Entrevista: Mês da Consciência Negra - Imagem da Palavra - Parte 1 [2012]. Disponível em: <https://www.youtube.com/watch?v=pwQ4Bxc87PE> Acesso em: 03 jan. 2019. Transcrito por Elen Karla Sousa da Silva.

. Escrevivências da Afro-Brasilidade: História e Memória. Revista Texturaafro, Editora Lê, 1992, Parte III.

LE GOFF, J. História e memória. Trad. Irene Ferreira; Bernardo Leitão e Suzana F. Borges. 6. ed. Campinas: Editora da Unicamp, 2012.

POLLAK, Michael. Memória, Esquecimento, Silêncio. Estudos Históricos, Rio de Janeiro, v. 2, n. 3, 1989, p. 3-15.

RICOEUR, Paul. A memória, a bistória, o esquecimento. Campinas: Ed. da Unicamp, 2007.

Recebido em: 31/08/2019.

Aprovado em: 22/10/2019. 